\title{
Enhancing Education to Avoid Complications in Endovascular Treatment of Unruptured Intracranial Aneurysms: A Neurointerventionalist's Perspective
}

\author{
(D) M. Goyal, (D). Fiehler, (D)W. van Zwam, (D).H. Wong, and (D).M. Ospel
}

\begin{abstract}
SUMMARY: It is of utmost importance to avoid errors and subsequent complications when performing neurointerventional procedures, particularly when treating low-risk conditions such as unruptured intracranial aneurysms. We used endovascular treatment of unruptured intracranial aneurysms as an example and took a survey-based approach in which we reached out to 233 neurointerventionalists. They were asked what they think are the most important points staff should teach their trainees to avoid errors and subsequent complications in endovascular treatment of unruptured intracranial aneurysms. One hundred twenty-one respondents (51.9\%) provided answers in the form of free text responses, which were thematically clustered in an affinity diagram and summarized in this Practice Perspectives. The article is primarily intended for neurointerventional radiology fellows and junior staff and will hopefully provide them the opportunity to learn from the mistakes of their more experienced colleagues.
\end{abstract}

A smart man makes a mistake, learns from it, and never makes that mistake again. But a wise man finds a smart man and learns from him how to avoid the mistake altogether.

\section{Roy H. Williams}

As neurointerventional fellows, we are bound to make mistakes. Human errors in neurointervention occur in up to $12 \%$ of cases, ${ }^{1}$ and they are, to some degree, unavoidable, but mentorship can prevent some of them from happening. The weighing of treatment risks and benefits is of particular importance for low-risk conditions such as unruptured intracranial aneurysms, in which complications weigh heavily on the neurointerventionalist. Thoughtful mentors will share their experiences and, most important, their errors and failures with us so that we can learn from their mistakes. What do experienced neurointerventionalists wish they had been told as fellows? We used endovascular

Received June 12, 2020; accepted after revision July 31.

From the Departments of Clinical Neurosciences (M.G., J.H.W., J.M.O.) and Radiology (M.G., J.H.W.), and Division of Neurosurgery (J.H.W.), University of Calgary, Calgary, Alberta, Canada; Department of Diagnostic and Interventional Neuroradiology (J.F.), University Medical Center Hamburg-Eppendorf, Hamburg, Germany; Department of Radiology and Nuclear Medicine (W.v.Z.), Cardiovascular Research Institute Maastricht, School for Mental Health and Sciences, Maastricht University Medical Center, Maastricht, the Netherlands; and Department of Radiology (J.M.O.), University Hospital of Basel, Basel, Switzerland.

Please address correspondence to Mayank Goyal, MD, PhD, Departments of Radiology and Clinical Neurosciences, Foothills Medical Centre, 1403 29th St NW, Calgary, AB, T2N2T9, University of Calgary, Calgary, AB, Canada; e-mail: mgoyal@ucalgary.ca; @johanna_ospel; @mayank_G0

Indicates article with supplemental on-line appendix and table. http://dx.doi.org/10.3174/ajnr.A6830 treatment of unruptured intracranial aneurysms as an example and took a survey-based approach in which we reached out to 233 neurointerventionalists to answer this question (mostly senior staff; for detailed demographics and countries of survey participants see Online Tables 1 and 2). Participants were asked the most important points staff should teach their trainees to avoid complications in endovascular treatment of unruptured intracranial aneurysms. One hundred twenty-one respondents (51.9\%) provided answers in the form of free text responses, which were thematically clustered in an "Affinity Diagram" (Online Appendix). This format was deliberately chosen to avoid narrowing the responses down to certain topics by suggesting topics or providing examples. The free text answers were then screened, and it was determined whether they contained $\geq 1$ thematically distinct message. If the latter was the case, the response was split accordingly. Responses were then manually clustered by identifying common themes. Thematically similar responses were clustered together. Those clusters with the largest number of responses were extracted and formed the basis for the article. They are shown in the Table and summarized below (for key recommendations, see also the Figure).

\section{Asking for Help}

Neurointerventional skills are learned progressively, and a realistic and honest appraisal of one's own skillset and limitations was considered crucial by most respondents. Fellows should know when to refer a case to a more experienced colleague and never be hesitant to reach out to colleagues for help and advice; not doing so means putting the patient at risk. 


\begin{tabular}{|c|c|c|}
\hline Response Cluster $^{a}$ & Explanation & Exemplary Responses $^{a}$ \\
\hline \multicolumn{3}{|l|}{ General advice } \\
\hline Humility and ethical standards & $\begin{array}{l}\text { Realistic appraisal of one's skillset and its } \\
\text { limitations }\end{array}$ & $\begin{array}{l}\text { "We need calm and honest fellows, not } \\
\text { cowboys" } \\
\text { "Be aware of overestimating your own skills" }\end{array}$ \\
\hline $\begin{array}{l}\text { Interaction with colleagues and } \\
\text { asking for advice }\end{array}$ & $\begin{array}{l}\text { Reaching out for advice and help from more } \\
\text { experienced colleagues when needed }\end{array}$ & $\begin{array}{l}\text { "Don't be a hero_-stop and ask!" } \\
\text { "Be comfortable referring for a second } \\
\text { opinion" }\end{array}$ \\
\hline $\begin{array}{l}\text { Critically revisiting complications } \\
\text { and their management }\end{array}$ & $\begin{array}{l}\text { Discussion of complications with colleagues in } \\
\text { and outside M\&M rounds and meetings, } \\
\text { constructive feedback, root-cause analysis }\end{array}$ & $\begin{array}{l}\text { "Show fellows their own complications and } \\
\text { deaths, and how to deal with them if there } \\
\text { was a second chance" } \\
\text { "Honestly self-review all cases in which [a] } \\
\text { complication has occurred and understand } \\
\text { what went wrong. Never blame it on device } \\
\text { quality or malfunction" }\end{array}$ \\
\hline \multicolumn{3}{|l|}{ Preprocedural phase } \\
\hline Indication and patient selection & $\begin{array}{l}\text { Patient-centered treatment decision-making, } \\
\text { knowing which patients one should not treat }\end{array}$ & $\begin{array}{l}\text { "Learn when to say no" } \\
\text { "What not to treat in the first 3-5 years of } \\
\text { practice" } \\
\text { "Knowing which patients can be safely } \\
\text { followed" }\end{array}$ \\
\hline Preoperative planning & $\begin{array}{l}\text { Thorough review of prior imaging, a priori } \\
\text { planning of specific procedure steps, } \\
\text { anticipation of potential problems and } \\
\text { alternative solutions }\end{array}$ & $\begin{array}{l}\text { "Study the 3D angio, don't rush, plan your } \\
\text { approach. What's the plan B, C?" } \\
\text { "Work-up each case very carefully and try to } \\
\text { predict complications" } \\
\text { "Before doing a procedure, think of everything } \\
\text { that can induce a procedural complication" }\end{array}$ \\
\hline $\begin{array}{l}\text { Keeping alternative treatment } \\
\text { options in mind }\end{array}$ & $\begin{array}{l}\text { Considering surgical options (clipping, sacrificing } \\
\text { the parent vessel) and watch-and-wait } \\
\text { strategies }\end{array}$ & $\begin{array}{l}\text { "Less emphasis on endovascular being the be-all } \\
\text { and end-all" } \\
\text { "Never forget that competent and adequate } \\
\text { surgical clipping is feasible and sometimes } \\
\text { ideal!" }\end{array}$ \\
\hline Theoretic knowledge & $\begin{array}{l}\text { Solid knowledge about cerebrovascular } \\
\text { anatomy }\end{array}$ & $\begin{array}{l}\text { "Be properly trained, both technical and } \\
\text { theoretical!, before you start." } \\
\text { "More training in some programs on how to } \\
\text { look at imaging" }\end{array}$ \\
\hline \multicolumn{3}{|l|}{ Intraprocedural phase } \\
\hline Technical skills & $\begin{array}{l}\text { Acquiring technical skills in a simulation } \\
\text { environment before performing real cases }\end{array}$ & $\begin{array}{l}\text { "Always be careful with patients and train a lot } \\
\text { in silicone models/computer simulators!!" } \\
\text { "Simulators are how you need to learn and } \\
\text { master the nuances of different cases, not } \\
\text { trial and error on patients" }\end{array}$ \\
\hline $\begin{array}{l}\text { Standardization and } \\
\text { simplification }\end{array}$ & $\begin{array}{l}\text { Standardization of procedure steps, } \\
\text { prespecified protocols for the management } \\
\text { of complications }\end{array}$ & $\begin{array}{l}\text { "Stick to the given protocols each and every } \\
\text { time" } \\
\text { "Meticulous planning of the procedure" } \\
\text { "Show all types of possible complications and } \\
\text { write protocols for how to deal with them" }\end{array}$ \\
\hline Knowing when to stop & $\begin{array}{l}\text { Recognizing the point at which continuing the } \\
\text { procedure will likely cause more harm than } \\
\text { benefit, avoiding the "perfection trap" }\end{array}$ & $\begin{array}{l}\text { "If you think that you can put one more coil, } \\
\text { that is [the] time to stop!" } \\
\text { "Don't let the best be the enemy of the good" } \\
\text { "How to reduce unnecessary and perfectionist } \\
\text { steps" }\end{array}$ \\
\hline
\end{tabular}

Note:-M\&M indicates morbidity and mortality.

${ }^{a}$ For a detailed overview of response clusters and individual responses, see the "Affinity Diagram" in the Online Appendix.

Many responses emphasized the importance of honestly discussing and revisiting complications and their management in an open and nonjudgmental environment, ${ }^{2}$ be it in morbidity and mortality rounds, ${ }^{3}$ interaction with colleagues, ${ }^{4}$ or professional society meetings.

\section{Treatment Indication}

Ensuring successful treatment requires picking the right patients in the first place. Participants advised fellows to perform a thorough risk-benefit analysis before every treatment decision. Knowing which cases not to treat in the early years of practice was considered key knowledge for fellows. ${ }^{5}$ Proper review of noninvasive imaging to anticipate and prevent potential complications and planning of alternative strategies, "having a plan A, B, and C" as one of the respondents stated, was thought to be essential to handle unexpected events.

The goal is to ensure that patients receive the best possible treatment, be it endovascular, surgical, or conservative ("watch 
Remain humble and honest with yourself and your patients, don't be afraid to ask for help

- Solid theoretical knowledge

- Staying up to date with the literature

- Simulator training

- Observing lots of cases
- Critical evaluation of treatment indication

- Good understanding of the natural history of disease

- Meticulous studying of the patient's imaging, planning

- Having a plan A, B, C

- Consulting staff if necessary
- Knowing when to stop

- Asking for help if needed

- Not being afraid of bailing out/ rescheduling with more experienced staff
- Honest analysis of all cases and complications

- Proper follow-up up on patients

- Maintaining data bases

- Participating in trials to generate evidence

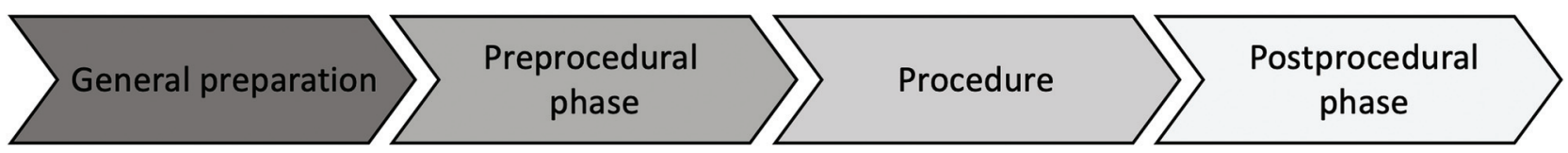

- Structured education: explaining in detail which complications can happen during any procedure and how to handle them
- Go through the procedure with your fellows, ask them what their plan A, B, C is

- Go through all possible complications and discuss prevention and management strategies
- Provide close supervision but resist the urge to take over

- Encourage them to ask for help and discourage "cowboy" behavior

Teach them to treat patients, not pictures
- Meticulous analysis of each case, constructive criticism

- Teach them to follow-up on their patients and to analyze their complications

Encourage fellows to be humble, continuously self-reflect and learn, even after their fellowship

\section{Advice for senior staff}

FIGURE. Key recommendations for fellows and senior staff on how to avoid complications in endovascular treatment of unruptured intracranial aneurysms regarding general preparation, preprocedural, intraprocedural, and postprocedural phases. The asterisk indicates that this advice also applies to junior staff.

and wait"), and this will require an open and unbiased discussion among physicians from different medical specialties, including diagnostic and interventional neuroradiology, neurosurgery, and neurology.

\section{Simulation Training and Standardized Procedural Steps}

Simulation training constitutes a safe environment to practice technical skills. ${ }^{6-10}$ Physicians believed that fellows should train as much as possible in a simulation environment to learn basic catheter skills before performing real cases. Standard operating procedures for every procedure step, close adherence to protocols for the management of intraprocedural complications, and choosing the simplest treatment approach possible were additional points physicians considered of high importance. ${ }^{11}$

\section{Safety}

Using a few devices well was thought to be much wiser than the use of a wide variety of new devices, for which safety and efficacy data are often limited: "keeping it as simple and safe as possible," as many of them put it. Accepting imperfection and avoiding unnecessary and dangerous perfectionist steps toward the end of a procedure were perceived crucial for fellows: "If you think that you can put one more coil, this is [the] time to stop."

Humans make mistakes, and they make them frequently. Neurointervention is no exception to this rule, and the stakes are high. The advice summarized in this article (see the Figure for key recommendations for fellows and senior staff) is intended to help fellows and junior staff "to be wise" as Roy H. Williams put it-that is, to learn from the mistakes of their more experienced colleagues.

Disclosures: Mayank Goyal—RELATED: Consulting Fee or Honorarium: Mentice, Comments: advice on acute stroke intervention; UNRELATED: Consultancy: Stryker, Medtronic, MicroVention; Patents (Planned, Pending or Issued): GE Healthcare, Comments: licensing agreement for systems of acute stroke diagnosis. Jens Fiehler-UNRELATED: Consultancy: Acandis, Cerenovus, Medtronic, MicroVention, Stryker, Penumbra; Grants/Grants Pending: Acandis, Cerenovus, Medtronic, MicroVention, Stryker, Route94*; Stock/Stock Options: Tegus; OTHER RELATIONSHIPS: CEO Eppdata. Wim van Zwam-UNRELATED: Payment for Lectures Including Service on Speakers Bureaus: Cerenovus, Stryker,* John H. Wong-UNRELATED: Stock/Stock Options: Fluid Biotech Inc, Comments: Cofounder and CEO of Fluid Biotech Inc. Johanna M. Ospel-UNRELATED: Grants/Grants Pending: Gottfried und Julia Bangerter Rhyner Stiftung, University of Basel Research Foundation, Freiwiliige Akademische Gesellschaft Basel, Comments: research scholarships. *Money paid to the institution.

\section{REFERENCES}

1. Gross BA, Jadhav AP, Jovin TG, et al. Neurointerventional "near morbidity": a candid appraisal of an early case series. Interv Neurol 2018;7:419-30 CrossRef Medline

2. Lyckholm L. Medical errors and medical culture: there is no easy way around taking responsibility for mistakes. BMJ 2001;323:570 CrossRef Medline

3. Mok PS, Tan EY, Baerlocher MO, et al. The role of morbidity and mortality meetings in interventional radiology. Eur J Radiol 2012;81:3344-47 CrossRef Medline

4. Fargen KM, Velat GJ, Lawson MF, et al. Enhanced staff communication and reduced near-miss errors with a neurointerventional procedural checklist. J Neurointerv Surg 2013;5:497-500 CrossRef Medline 
5. Eskey CJ, Meyers PM, Nguyen TN, et al; American Heart Association Council on Cardiovascular Radiology and Intervention and Stroke Council. Indications for the performance of intracranial endovascular neurointerventional procedures: a Scientific Statement from the American Heart Association. Circulation 2018;137:e661-89 CrossRef Medline

6. Kreiser K, Gehling K, Zimmer C. Simulation in angiography: experiences from 5 years teaching, training, and research [In German]. Rofo 2019;191:547-52 CrossRef Medline

7. Kreiser K, Ströber L, Gehling KG, et al. Simulation training in neuroangiography: validation and effectiveness. Clin Neuroradiol 2020 April 27. [Epub ahead of print] CrossRef Medline
8. Spiotta AM, Rasmussen PA, Masaryk TJ, et al. Simulated diagnostic cerebral angiography in neurosurgical training: a pilot program. $J$ Neurointerv Surg 2013;5:376-81 CrossRef Medline

9. Bechstein M, Buhk JH, Frolich AM, et al. Training and supervision of thrombectomy by Remote Live Streaming Support (RESS): randomized comparison using simulated stroke interventions. Clin Neuroradiol 2019 Dec 20. [Epub ahead of print] CrossRef Medline

10. Kreiser K, Gehling KG, Strober L, et al. Simulation training in neuroangiography: transfer to reality. Cardiovasc Intervent Radiol 2020;43:1184-91 CrossRef Medline

11. Frei D, McGraw C, McCarthy K, et al. A standardized neurointerventional thrombectomy protocol leads to faster recanalization times. J Neurointerv Surg 2017;9:1035-40 CrossRef Medline 